\title{
Manuel Enríquez: artífice del Foro Internacional de Música Nueva. Estudio de un campo cultural
}

\author{
Manuel Enriquez: architect of the International Forum \\ of New Music. Study of a cultural field.
}

\author{
por \\ Gabriel Macias Osorno \\ Universidad Autónoma Metropolitana, México \\ gabmaos@gmail.com
}

El estudio analiza la creación y consolidación del Foro Internacional de Música Nueva Manuel Enríquez desde la teoría de campo de Pierre Bourdieu. Dicho certamen, que anualmente tiene lugar en México y cuya finalidad es la de presentar música de concierto actual, ha constituido un escenario musical de referencia para dicho país de 1979 a la fecha. Por tanto, a lo largo de este escrito se estudia el surgimiento y desarrollo de este espacio intentando comprender el contexto en que tuvo lugar, su fundación y cómo llegó a consolidarse en el panorama musical mexicano, a la vez que discernir la importancia que tuvo Manuel Enríquez en tanto artífice del Foro. Para ello se genera un trazo histórico por el que es posible comprender una parte importante de su funcionamiento, esto es, observar cómo está constituido, cuáles son sus dinámicas y qué tipo de habitus ha generado.

Palabras clave: Manuel Enríquez, Foro Internacional de Música Nueva, Historia musical de México siglo XX, Música contemporánea, Festivales de música, Campo cultural.

This article analyzes the creation and consolidation of the Foro Internacional de Música Nueva Manuel Enriquez from the field theory of Pierre Bourdieu. This event which takes place annually in Mexico and whose purpose is to present current concert music has been a musical reference scenario from 1979 to date. Therefore, throughout this paper the advent and development of this space is studied trying to understand the context in which it took place, its foundation and how it came to be consolidated in the Mexican music scene, while discerning the importance that had Manuel had Enriquez as the architect of the Forum. For this, a historical line is generated through which it is possible to understand an important part of its operation, that is, to observe how it is constituted, what its dynamics are and what kind of habitus it has generated.

Keywords: Manuel Enríquez, Foro Internacional de Música Nueva, Mexican music history 20th century, Contemporary music, Music festivals, Cultural field. 


\section{INTRODUCCIÓN ${ }^{1}$}

El Foro Internacional de Música Nueva Manuel Enríquez es un certamen que anualmente tiene lugar en México desde 1979, y cuya finalidad es presentar música de concierto actual o de las últimas décadas, principalmente. Dicho espacio, reconocido tanto a nivel nacional como internacional, es un organismo con extensa historia que cuenta ya con más de cuarenta emisiones, distribuidas a lo largo de igual número de años de manera ininterrumpida.

El presente ensayo pretende abordar algunos elementos de dicho encuentro y contribuir con ello al mejor conocimiento de un objeto de estudio de estimable relevancia ${ }^{2}$. Concretamente, se estudia el surgimiento del Foro y su desarrollo desde la teoría de campo, como la define Pierre Bourdieu, es decir, en tanto espacio social de acción y de influencia en el que confluyen relaciones sociales específicas, atravesadas por una estructura que las condiciona según la posesión de formas determinadas de capital (Bourdieu 1990: 109111). La fundación del Foro se entiende así como el surgimiento de un campo nuevo en un contexto social determinado, esto es, que su creación no solo significó la apertura de un espacio para hacer oír determinadas propuestas sonoras, también implicó, paralelamente, la generación de un entramado social complejo en torno a este, es decir, una esfera de interacción social estructurada y estructurante, conformada por un conjunto de agentes sociales, en este caso especialistas en interpretación, composición, crítica musical, gestión, académicas y académicos.

En la investigación se presupone, pues, que el Foro al consolidar por sí solo un campo, genera una estructura particular, donde se dan relaciones sociales, no necesariamente percibidas simétricamente, cuestión que propicia distintos niveles de acuerdos y tensiones. Más aún si se piensa que en un espacio dedicado a la promoción de la música nueva, lo nuevo no será un término estrictamente neutro sino un tanto arbitrario, que supone una elección -o discriminación- de qué cabe o no en esta categoría. De modo que, a lo largo del escrito, lo nuevo se entiende como una construcción que instituye sus propios parámetros y mecanismos para establecer lo que puede o no ser apto para ubicarse dentro del Foro, al tiempo que estos le van confiriendo una estructura particular, sus propias reglas de acción y lugares de poder.

Siguiendo los planteamientos del sociólogo francés, los condicionamientos asociados a una clase particular de modos de existencia producen habitus, esto es, sistemas de disposiciones duraderas y transferibles, como principios generadores y organizadores de prácticas y de representaciones, que tienden a parecer como necesarias, incluso como naturales, por el hecho de que están en el principio de los esquemas de percepción y de apreciación en los que son aprehendidas. Por tanto, el habitus origina prácticas individuales y colectivas que van más allá de personajes concretos, y asegura la presencia activa de las experiencias pasadas, lo mismo que garantiza la conformidad de las prácticas y su constancia en el transcurso

1 Este trabajo conforma parte de la investigación realizada en el programa de posgrado en Historia del Arte de la Universidad Nacional Autónoma de México (UNAM). El proyecto contó con el apoyo de una beca del Programa de Apoyo a los Estudios de Posgrado (PAEP) otorgada por la propia universidad.

2 A pesar de la importante trayectoria del Foro, a la fecha no existen estudios académicos o de documentación sobre éste, o algún escrito que hable en profundidad de su fundación, de sus programaciones y conciertos, o de los músicos y compositores que han actuado en él. Aparte de algunas menciones y glosas en bibliografía referida a instituciones culturales de México, no hay una publicación que vaya más allá de estos esfuerzos. Básicamente hay dos textos publicados en torno al Foro: la sección que Aurelio Tello desarrolla en el libro México: Su apuesta por la cultura, y el espacio que le confiere Armando Gómez Rivas en su artículo "Instituciones musicales. La conformación de una cultura musical en el México del siglo XX”. Véase: Tello 2003: 305-307 y Gómez 2013: 371-415. 
del tiempo (Bourdieu 2009: 86-88). Esto supone que en el Foro existen estructuras sociales internas, incorporadas en forma de esquemas de percepción, de pensamiento y de acción, mediante los que produce sus prácticas. En otras palabras, el Foro, en tanto que campo, también genera su propio habitus ${ }^{3}$.

En síntesis, este trabajo busca desdoblar parte de la compleja estructura de este campo. Intenta aproximarse a comprender el contexto en que tuvo lugar su fundación, trata de detectar las condiciones que hicieron factible la apertura de este campo en el panorama musical mexicano y cómo llegó a consolidarse, así como discernir la importancia que tuvo Manuel Enríquez, en tanto artífice del Foro. Para ello se pretende generar un trazo histórico en el que sea posible comprender una parte importante de su funcionamiento, esto es, observar cómo está constituido, cuáles son sus dinámicas y qué tipo de habitus ha generado; se quiere incluso hacer visibles algunas de sus contradicciones.

Para poder esbozar una interpretación acerca del surgimiento y desarrollo del Foro, se indaga especialmente en los primeros treinta y siete años de vida del certamen (19792015). Para ello se revisaron fuentes hemerográficas y programas de mano, y se realizaron entrevistas a actores cercanos al citado encuentro. Asimismo, fue imprescindible acudir a obras que compilan críticas, entrevistas, cartas y otros documentos, tanto de la época cercana a la fundación del Foro como de su desarrollo, para comprender qué hizo necesaria su existencia y cómo este fue recibido en el medio musical mexicano en sus distintas fases.

El escrito consta de tres apartados. El primero ofrece el marco contextual que propició la apertura de espacios afines a la "nueva música" y particularmente el Foro de Música Nueva. Las dos subsecuentes secciones abordan el desarrollo del Foro. Primeramente, es analizado desde el momento de su fundación (1979) hasta la emisión número XVI (1994), es decir, durante el ciclo vital de Manuel Enríquez. Luego, se da paso a revisar lo sucedido tras la desaparición del compositor cuando la organización del certamen experimentó varias reestructuraciones que incluyeron las designaciones de nuevos responsables.

\section{SURGIMIENTO DEL FORO INTERNACIONAL DE MÚSICA NUEVA}

El 7 de abril de 1979 fue inaugurada en la Ciudad de México la primera emisión del Foro Internacional de Música Nueva, hoy conocido como Foro Internacional de Música Nueva Manuel Enríquez (FIMNME) ${ }^{4}$. Este organismo, impulsado por el citado compositor desde el Centro Nacional de Investigación, Documentación e Información Musical (Cenidim) ${ }^{5}$, dependiente del Instituto Nacional de Bellas Artes (INBA), ha tenido significativa importancia en el devenir de la música académica de dicho país, pues entre sus prioridades a lo largo de sus ya más de cuatro décadas ha estado, precisamente, la divulgación de la nueva música de México y de otras latitudes ${ }^{6}$.

En sus inicios el Cenidim, bajo la dirección de Carmen Sordo Sodi, otorgó cierta preeminencia a trabajos orientados hacia la investigación folclórica y el periodo virreinal.

3 Para ahondar en los conceptos de campo y habitus, véase Bourdieu 2002.

4 Fundamentalmente el Foro se realiza en la Ciudad de México. En épocas más recientes ha tenido presencia en otros estados. Quizá su extensión más notable -aunque modesta- y constante la tiene en Morelia, Michoacán en cooperación con el Centro Mexicano para la Música y las Artes Sonoras.

5 Creado en 1973 por decreto presidencial, su antecedente fue la Sección de Investigaciones Musicales, dependiente del Departamento de Música de la Secretaría de Educación Pública (SEP). Véase Ruiz 1999: 476-478.

$6 \mathrm{Al}$ contar con apoyo de instituciones gubernamentales y conformar parte de los órganos de difusión cultural estatales, desde sus inicios y hasta la actualidad, sus conciertos son gratuitos. 
Cuando en 1978 el violinista y compositor Manuel Enríquez asumió la dirección del centro, este dio un giro importante, al focalizarse en la divulgación y fomento de la música de los compositores activos, poniendo particular atención en "la producción de todos los jóvenes de vanguardia" 7 . Así, entre las actividades sustantivas de la gestión de Enríquez estuvo la organización de recitales, la creación de un Taller de Composición y la reubicación del Laboratorio de Música Electrónica, el que se trasladó al centro desde su sede original en el Conservatorio Nacional de Música. Ambos espacios estarían destinados al estudio de nuevas manifestaciones como el teatro musical, la ópera total o el video-art ${ }^{8}$. Pero entre todas las iniciativas y proyectos desarrollados bajo su dirección, la creación y organización del Foro Internacional de Música Nueva ocupó un sitio primordial.

Para entender mejor el contexto en el que surge el Foro, conviene apuntar algunos antecedentes de la situación de la música en México, especialmente a partir de la importante brecha que se produjo tras el declive de las corrientes nacionalistas. De acuerdo con Aurelio Tello, a finales de la década de 1950 y principio de la siguiente, comenzó a propagarse la obra de una nueva generación de compositores que implementaron novedosas técnicas y recursos composicionales. Las propuestas de muchos de ellos marcaron significativa distancia con las convenciones nacionalistas que empleaban los seguidores de dichas tendencias, algunos de ellos aún en plena actividad. Con este grupo de renovadores comenzarían a fluir en México corrientes musicales caracterizadas por la heterodoxia y la pluralidad de estilos (Tello 2010: 516).

$\mathrm{Al}$ darse por terminada la "obligación" del mensaje nacionalista para la composición -como sugiere Yolanda Moreno Rivas-, "ésta pudo aspirar a una autonomía estética" (Moreno 1994: 58). Tal reacción explica, cuando menos en parte, que la composición en México estuviera en posibilidad de tomar varias direcciones.

Las décadas de los sesenta y setenta vieron la eclosión de los movimientos de vanguardia en México; el número de compositores que se interesaron por estas corrientes aumentó, lo mismo que las obras adscritas a tales vertientes. Sin embargo, las obras producidas no contaron con el suficiente apoyo oficial para su interpretación. Rara vez llegó a contemplarse alguna de ellas en las programaciones de las orquestas sinfónicas mexicanas; tampoco resultó fácil conseguir la publicación y grabación comercial de las mismas (Tello 2011: 85). Como apunta Moreno Rivas, esta generación de compositores, pese a que no asumió propiamente una actitud polémica ante el nacionalismo o conflictiva hacia las instancias artísticas habituales, experimentó "una transición difícil que se tradujo en la falta de apoyos del Estado, una desprotección de la composición nueva y una disminución en la demanda de los públicos para las obras mexicanas" (Moreno 1994: 58).

Desde la perspectiva en la que se está pensando el Foro, puede entenderse que este contexto adverso que padecían los nuevos compositores se debe a la dinámica propia de otros campos, como los que conformaban las orquestas sinfónicas activas y las instituciones culturales de la época. Los compositores más jóvenes, al no pertenecer a estas estructuras y no compartir valores propiamente afines a los de aquellos campos, quedaban al margen de estos ${ }^{9}$. En consecuencia, se generó un contexto de relativa exclusión, como podían llegar a plantearlo ciertos sectores de la crítica en los años sesenta y setenta. Por ejemplo,

7 "El Centro de Investigaciones Musicales del INBA, al rescate de la actualidad sonora de México", Uno más uno (21 de enero, 1978), p. 19.

8 "Rescate, investigación y difusión de valores nacionales, propósito del INBA: J. J. Bremer", Uno más uno (24 de enero, 1978), p. 19.

9 La marginación de un individuo o un grupo de ellos en el espacio que comprende un campo debe entenderse como algo parcial, ya que si fuera total el campo se desestructuraría. Véase Picún 2006: 191. 
José Antonio Alcaraz en 1961 expresaba que la vida musical mexicana se había estancado y carecía de interés, pues lo único que se podía oír en México era a unos cuantos compositores europeos (Sosa 2008: 33-34). Más de quince años después, el mismo crítico seguía insistiendo en que el aislamiento musical se acentuaba cada vez más, pues, salvo excepciones, no parecía existir voluntad por hacer oír obras y autores nuevos o poco habituales (Alcaraz 1977). También la musicóloga Esperanza Pulido, desde las páginas de Heterofonía, revista fundada y dirigida por ella, lamentaba en 1978 la limitada oferta de la Orquesta Filarmónica de la Universidad, pues la programación general de ese año contemplaba solo dos obras mexicanas: una de Carlos Chávez y otra de Silvestre Revueltas; ninguna latinoamericana o de riguroso estreno (Pulido 1978: 33).

Esta situación era más que desfavorable para los jóvenes compositores mexicanos, como lo hacía ver el escritor Juan Vicente Melo, para quien la joven música mexicana era una generación huérfana, que padecía la indiferencia de las autoridades oficiales de la música (Melo 1994: 172-173). Otras voces, incluidas las de algunos compositores aquejados por la situación, manifestaron su opinión al respecto. Leonardo Velázquez denunció la existencia de grupos cerrados que no permitían la entrada a los jóvenes compositores, situación que se hacía patente en los programas de la Orquesta Sinfónica Nacional (Melo 1994: 105-106). El escepticismo de Mario Kuri Aldana se expresaba en estos términos:

Los jóvenes compositores mexicanos (así se nos llama obedeciendo, no tanto a la verdad cronológica, como al deseo de distinguirnos del racimo que encabezan los maestros Carlos Chávez, Blas Galindo y Rodolfo Halffter) [...] En la superficie vivimos una especie de bonanza musical. Nuestra venerable Sinfónica Nacional no tiene ya ni con mucho la exclusiva de la música clásica. Finalmente organismos sinfónicos y de cámara nacen y se desarrollan [...] Los conciertos se multiplican y las temporadas [se] suceden ininterrumpidas. No sería descabellado suponer, a partir de este esplendor externo, que los compositores nos afanamos día y noche tratando de cubrir la intensa demanda de obras de estreno y sin embargo, no habría nada más alejado de la verdad. [...] Para cualquiera de nosotros 'meter una obra' es un poco como sacarse la lotería [...] (Kuri Aldana 1976: 10-13).

Joaquín Gutiérrez Heras, si bien señalaba en 1964 la indiferencia que existía hacia la música contemporánea subrayando el hecho de que "un viejo grupo de nacionalistas" aún cultivaban el estilo que se había desarrollado durante los años treinta, advertía, por otra parte, acerca del incremento en la actividad de músicos, compositores y aficionados que no esperarían a que los patrocinios de instancias oficiales ofrecieran beneficios a su favor (Carredano 2000: 108-109). Efectivamente, al mismo tiempo que aparecían las críticas al contexto desfavorable, empezaron a surgir los intentos por revertirla. Ejemplo de esto fue el grupo Nueva Música de México -al que pertenecieron Manuel Enríquez y muchos otros compositores-, agrupación que, en palabras de Leonora Saavedra, encontraría su vínculo, no por una posición estética en común, sino por el deseo de lograr una apertura hacia la música de su generación en la programación de las instituciones musicales mexicanas (Saavedra 1999: 677).

En términos generales, de acuerdo con lo reportado por algunos críticos, músicos y escritores de asuntos musicales, se hacía necesario realizar un esfuerzo por difundir distintas músicas producto de transformaciones y de cambios profundos en la manera misma de entender la música. Hacían ver la necesidad de generar otro tipo de espacio para las músicas recientes en donde ya no había una correlación entre estas y las estructuras de difusión existentes. En el contexto global de aquellas décadas fue determinante la puesta en cuestión de valores largamente establecidos tanto en lo que respecta a la sociedad como a las expresiones artísticas, incluidas las musicales. 
Como es sabido, el contexto bélico de la primera mitad del siglo XX direccionó una reestructuración de valores y cuestionamientos. Señala el historiador Eric Hobsbawm que el mundo posterior a la era de las catástrofes generó una de las más revolucionarias alteraciones de la vida humana de que se tiene noticia. Además, se experimentó un desplazamiento geográfico de los centros tradicionales (europeos) de la cultura de élite, y de los límites entre lo que es y no clasificable unívocamente como "arte" (Hobsbawm 1995: 495-497). En el campo de la música, estos procesos repercutirían en cambios significativos en su entendimiento y realización.

Si bien ya existían antecedentes que tendían a una renovación de las estructuras musicales imperantes hasta ese momento, tras la segunda conflagración mundial estas se maximizaron. Es importante recordar que dichos cambios respondían a procesos largos, como apunta Pierre Schaeffer en su Tratado de los objetos musicales (1966), al señalar que el campo de lo musical se había expandido durante los últimos cien años en distintas direcciones, a razón de cuando menos tres importantes hechos: la investigación etnográfica, la música experimental y el cuestionamiento que los compositores habían hecho del sistema musical occidental (citado en Molino 2011: 122). Además de lo señalado por Schaeffer, otros factores de diversa índole incidieron en la transformación de la música. Baste señalar la disolución de los grandes imperios europeos a inicios del siglo XX, los cambios en los modelos económicos, el desarrollo tecnológico, la transformación de las comunicaciones, y varias condiciones que devinieron en permutas sociales, económicas, políticas y culturales.

Un ejemplo de esto se encuentra en la Alemania de la posguerra cuando, en forma paralela a su reconstrucción total, renovaba diversos aspectos de su vida musical. De hecho, en poco tiempo se convirtió en uno de los principales campos de acción de las nuevas músicas, teniendo especial relevancia en ello la labor de los cursos internacionales de verano que tenían lugar en la ciudad de Darmstadt. Estos encuentros -activos desde 1947- se convirtieron en un movimiento internacionalista donde se difundían las nuevas teorías musicales y se daban cita compositores provenientes de muchas partes del mundo (Marco Aragón 2002: 322-324).

En otros lugares del orbe igualmente se realizaron exploraciones que ampliaron las posibilidades para la composición. Mientras que en Francia germinó el movimiento de la música concreta en el marco de la radiodifusión francesa (RTF), y en Estados Unidos se exploraban posibilidades para el lenguaje musical implementando sintetizadores en el Columbia-Princeton Electronic Music Center, en la propia Alemania se daba un nuevo tratamiento al sonido por medio de la electrónica.

Las tendencias emergentes en aquellos países se propagaron, ganando adeptos en numerosos países. En México, algunos músicos se involucraron seriamente en ellas, llegando incluso a participar en los cursos de Darmstadt, a realizar estancias de estudio en importantes centros de investigación musical, y a recibir las enseñanzas de renombrados músicos adscritos a dichas corrientes. Fue el caso de Manuel Enríquez.

Si bien la trayectoria musical de Enríquez comenzó con una formación de corte "convencional", su inquietud por lo nuevo quedaría de manifiesto desde el primer momento, pero especialmente a partir de 1955, cuando se trasladó a Estados Unidos y se matriculó en la Juilliard School of Music de Nueva York, donde entró en contacto con músicas y horizontes artísticos de diversas tendencias. A su regreso a México, empezó a tener un lugar importante entre los compositores de su generación y, para los años sesenta, no solo era considerado uno de los compositores de vanguardia más sobresalientes del país, sino también comenzó a recibir constantemente encargos internacionales y su obra cobró presencia en festivales y conciertos de música contemporánea tanto en Europa como en América (Saavedra 1999: 677-683). 
Posteriormente, en 1971, este músico originario de Ocotlán, Jalisco, obtuvo una beca de la Fundación Guggenheim, la que le permitió desplazarse a Estados Unidos y Europa. De esta época datan sus primeras incursiones en la creación interdisciplinaria, con presentaciones de teatro musical, espectáculos multimedia, happenings y "anti-conciertos". (Saavedra 1999: 677-683).

La profusa actividad de Enríquez en el terreno de la música contemporánea lo apuntaló como uno de los mexicanos de mayor peso en la llamada música de vanguardia. Fue el primer compositor en el medio nacional en introducir las manifestaciones surgidas después del serialismo integral: módulos aleatorios, grafismo, combinación de contextos instrumentales y electrónicos en simultaneidad, multimedia, nuevas articulaciones, el teatro musical y la música para cinta (Alcaraz 2001: 48, 52).

La obra de Enríquez, que alcanzó más de un centenar de partituras y prestancia internacional, trazó significativas rutas en el devenir musical mexicano y fue decisiva en la ruptura con la vertiente nacionalista (Aharonián 1994: 121-126). Para Aurelio Tello, el lenguaje musical de Enríquez marcó una tendencia en su generación, y trazó la pauta de las condiciones de la música en México desde la mitad de siglo pasado hasta su conclusión ${ }^{10}$. Asimismo, Enríquez también se hizo presente en las estructuras gubernamentales de la música de México en las que llegó a ocupar cargos importantes. Aparte de la ya citada dirección del Cenidim (1978-1985), dirigió el taller de composición del mismo centro (1977), fue parte del Consejo Técnico de la Orquesta Sinfónica Nacional, profesor del Conservatorio Nacional de Música (desde 1968) y director de este (1972-1973), además de jefe del Departamento de Música del INBA (1988-1991) (Enríquez, Tello y De Andrade 2017: 6). Teniendo en cuenta el interés del músico jalisciense por las nuevas manifestaciones musicales y sus contactos con diversos compositores y lugares identificados con las corrientes de vanguardia, lo mismo que su cercanía con varias de las instituciones culturales de considerable importancia en México, resulta congruente que tuviera la inquietud de generar en dicho país espacios consagrados a la expresión de esta música.

Previo a la fundación del Foro guiada por Enríquez, hubo distintas iniciativas y proyectos encaminados a la promoción y creación de las músicas nuevas. En principio, autores como Manuel Rocha Iturbide han referido a los movimientos de vanguardia surgidos en México en los años veinte como un precedente para las tendencias que se dieron medio siglo después en la creación mexicana (Rocha 2012: 217, 219)11. Carlos Chávez también sembró antecedentes importantes. De particular interés son sus escritos "Música y física" y "Los instrumentos eléctricos de reproducción musical" publicados en 1932, además de su libro Toward a new music: Music and electricity (1937). En estos documentos, Chávez se refiere a algunos principios de lo que más adelante se denominaría música electrónica. Efectivamente, Chávez "se interesó por las posibilidades existentes en la tecnología para poder crear nueva música, pero nunca osó ser uno de los protagonistas de esas nuevas estéticas" (Rocha 2012: 228).

Más adelante, como ya se señalaba, en 1959 Manuel Enríquez participaría en la fundación de Nueva Música de México. Cerca de diez años después, también en el marco de la ciudad de México, nuevamente Enríquez, ahora junto con Mario Lavista, José Luis González y Héctor Quintanar, fundan la Sociedad de Música Contemporánea. En 1970, bajo iniciativa de Lavista, irrumpió el grupo de improvisación colectiva Quanta, ensamble

10 Tello, Aurelio (2014), Conferencia en torno a Manuel Enríquez, dictada en el marco del XXXVI Foro Internacional de Música Nueva, México, Sala Adamo Boari del Palacio de Bellas Artes (27 de mayo).

11 Se refiere al movimiento estridentista aglutinado en torno a la figura del poeta Manuel Maples Arce. 
experimental que se distinguió por su capacidad de transgredir numerosas convenciones musicales (véase Alonso 2014).

Igualmente, destaca en los primeros años sesenta la dinámica actividad del departamento de Difusión Cultural de la Universidad Nacional Autónoma de México (UNAM), mediante el proyecto de la Casa del Lago ${ }^{12}$. La compositora Alicia Urreta subrayaba la importancia que tuvieron para ella y sus contemporáneos los conciertos realizados en la Casa del Lago, donde los músicos de su generación y otros más jóvenes tuvieron oportunidad de involucrarse tanto en la parte organizativa como en la interpretación de las obras presentadas, o bien dando a conocer sus propias composiciones al mismo tiempo que se familiarizaban con repertorios contemporáneos poco difundidos (González y Saavedra 1982: 95-96).

De igual importancia fue el papel de la Universidad Autónoma Metropolitana (UAM) en el impulso de las nuevas músicas y sus creadores, luego de su fundación en la capital mexicana en 1974. También sobresale el festival de música contemporánea organizado en el Conservatorio Nacional de Música, lo mismo que el arribo a México -a finales de la década del sesenta- de importantes figuras de la vanguardia ecuménica: Pierre Schaeffer, Karlheinz Stockhausen o Jean-Étienne Marie, y la subsecuente presencia de John Cage ${ }^{13}$.

En 1970 el ingeniero Raúl Pavón y el compositor Héctor Quintanar fundaron el Laboratorio de Música Electrónica en el Conservatorio Nacional y cuatro años más tarde, organizado por Difusión Cultural UNAM, tuvo lugar el primer seminario de música electrónica (Prieto 2013: 24-25). Más afín al proyecto de Enríquez es el Festival Hispano-Mexicano de Música Contemporánea organizado entre 1973 y 1983 por los músicos Alicia Urreta y Carlos Cruz de Castro. De igual manera, a finales de la década de 1970 el compositor Antonio Russek creó el Centro de Investigación Independiente Musical y Multimedia (CIIMM) (Prieto 2013: 65).

Sin restar méritos al dinámico proyecto que impulsaba Enríquez, es claro que todas estas iniciativas -algunas más fugaces que otras- de una u otra forma habían abierto el camino para la puesta en marcha de este espacio dedicado exclusivamente a la música nueva. Si bien en ello fue decisivo el momento coyuntural que se vivía, no sería menos importante para el éxito de esta empresa que dicha iniciativa fuera obra de una personalidad tan potente, y con un estimable prestigio internacional.

\section{EL FORO EN TIEMPOS DE ENRÍQUEZ}

El impulso a lo nuevo fue sin duda el principal objetivo del Foro, pues este se abrió con el propósito de dar a conocer las novedosas corrientes musicales y reunir a compositores e intérpretes, tanto del país como del extranjero, inmersos en estas tendencias ${ }^{14}$. Ciertamente, muchas de las obras presentadas en sus primeras emisiones, previo al surgimiento de este espacio, hubieran sido difíciles de encontrar programadas y poco conocidas, sobre todo desde el ámbito de la difusión institucional. Así, en los primeros años se verificaron

12 Recinto cultural universitario ubicado en el bosque de Chapultepec de la Ciudad de México.

13 Jean-Étienne Marie estuvo en México en 1968, lo mismo que Pierre Schaeffer (no viajaron juntos) quien tuvo participación en el citado festival de música contemporánea del Conservatorio con una conferencia. Stockhausen visitó México en 1969, mientras que John Cage lo hizo en 1974. Este compositor y Manuel Enríquez dieron presentaciones en la ciudad de Monterrey en torno a la música electrónica. Datos en Rocha 2004 [esta referencia no aparece en la bibliografía] y De Andrade 2014. Respecto de Cage, Vilar y Alonso (2012: 280) mencionan que también estuvo en México en 1976 invitado por la Coordinación de Difusión Cultural de la UNAM, dirigida en ese entonces por Mario Lavista.

14 Programa de mano del ler Foro Internacional de Música Nueva. 
conciertos con instrumentos inusuales, con estructuras originales para presentar las obras, con diferentes tipos de interacciones intérprete-compositor, lo mismo que se atestiguó un sinnúmero de estrenos nacionales y mundiales.

Para entonces, fue constante encontrar programadas obras de teatro experimental, música de cámara con coreografías y electroacústica, medios múltiples, interdisciplina o "espectáculos multimedia"15. Asimismo, cobraron protagonismo algunas combinaciones instrumentales que para entonces eran poco usuales. Igualmente, instrumentos relegados por los repertorios más tradicionales -como la tuba, el clarinete o las percusiones- cobraron papeles protagónicos. De modo que, así como señaló Yolanda Moreno Rivas, el Foro posibilitó ver el desarrollo de un nuevo tipo de solistas sui generis, al tiempo que fraguaba y se conocía a una nueva generación de intérpretes (Moreno 1980: IX)16.

No obstante el ánimo de inclusión y apertura que pudo promover el certamen creado por Manuel Enríquez, es importante considerar que desde su gestación se generaron diferentes niveles de relaciones en las que estaban imbricados, desde los propios compositores que participan en los programas de conciertos, el propio Enríquez -a quien durante las primeras dieciséis emisiones le correspondió definir en buena medida lo que debía ser incluido o excluido-, hasta instancias institucionales gubernamentales. No hay que olvidar que el Foro dependía -aún depende- de un organismo federal como el INBA, por tanto, al momento en que se concretó el proyecto del Foro, este también pasó a formar parte de una estructura institucional amplia. Se tornó pues en un terreno de acción en donde el Estado cumple con una labor determinada, cuestión que incide en la estructura y orientación que asumió el certamen en cuanto a su programación y a los espacios en los que se ha desarrollado ${ }^{17}$.

Retomando la idea de campo de Bourdieu, el Foro no es un campo con total autonomía, por lo que también tiene relación con otras esferas, como las instituciones culturales vigentes en su época -por ejemplo-, que también llegaron a incidir en el desarrollo del certamen. Esto significa que no todo se concentraba en la figura de Enríquez; él también estaba obligado a hacer ciertas concesiones. Si bien era él quien hacía la programación incluyendo obras que le interesaban o le proponían, muchas veces por razones diversas debía sujetarse a lo que se lograba conseguir ${ }^{18}$. En otras ocasiones, la elección de las obras podía estar relacionada con la facilidad para su realización, con los espacios disponibles para ejecutarlas, con los intérpretes que conseguía o con músicos y agrupaciones de procedencia internacional que podían trasladarse a México vía convenios con representaciones culturales

15 "El Foro Internacional de Música Nueva se efectuará del 17 al 27 de abril en el D.F." Uno más uno (10 de abril, 1980), p. 18.

16 No ha de pasarse por alto la encomiable labor que el Foro de la era de Enríquez hizo en materia de promoción e impulso de algunos instrumentistas y agrupaciones. Precisamente, dicho certamen se convirtió en un sitio donde una vez al año se podía escuchar a compositores, solistas o conjuntos que pertenecían a una nueva generación. Así, daría lugar y contribuiría a la consolidación de ensambles e intérpretes especializados en los nuevos repertorios. Entre los artistas y agrupaciones que constantemente pisaban los escenarios del Foro, pueden citarse: Quinteto de Alientos de la Ciudad de México, Cuarteto Latinoamericano, La Camerata, Trío Neos, Dúo Castañón-Bañuelos; solistas como Alberto Cruz Prieto, Álvaro Bitrán, Marielena Arizpe, Juan Carlos Laguna, Horacio Franco, Lidia Tamayo, Margarita Pruneda o Lourdes Ambriz; compositores como Antonio Russek, Roberto Morales, Raúl Pavón, Vicente Rojo, Jorge Córdoba o Javier Álvarez; directores como Sergio Cárdenas o Eduardo Soto Millán, son algunos ejemplos.

17 Tras la salida de Enríquez como director del Cenidim, el Foro dejó de depender de ese centro y su organización quedó bajo responsabilidad de la hoy denominada Coordinación de Música y Ópera del INBA.

18 Soto Millán, Eduardo. Entrevista con el autor. Ciudad de México, 19 de mayo de 2014. 
de instituciones y embajadas, pues el presupuesto que tenía el Foro era restringido y esto también incidía en su desarrollo ${ }^{19}$.

De igual modo, y de acuerdo con Eduardo Soto Millán, Manuel Enríquez tenía colaboradores cercanos que incidían en el desarrollo del Foro -como Mario Lavista- que eran los compositores "con mayúscula" del momento ${ }^{20}$. De ellos era común encontrar sus obras programadas, esta situación llegó a relegar a otros compositores activos que tenían menos trayectoria o no eran cercanos al círculo de Enríquez ${ }^{21}$. Aun así, el Foro estaba fundamentalmente bajo la dirección de Manuel Enríquez: en él recayeron principalmente las decisiones de lo que se programó, situación con la que no coincidieron todos los que participaban o tenían interés en el festival. Esto dio lugar a diferentes visiones de lo que podría haber sido dicho espacio.

Efectivamente, el Foro de Música Nueva fue secundado por otros compositores mexicanos que perseguían objetivos afines a los de Enríquez. En términos generales, resultaba encomiable su decidida labor de proyección y apoyo a los autores nacionales (Moreno 1980: IX), lo mismo que a expresiones artísticas que hasta entonces habían quedado al margen en instituciones y escuelas de música (Cardona 1982: 22) 22. A pesar de su aceptación, desde momentos tempranos de su desarrollo comenzó a ser objeto de cuestionamientos y diversos tipos de críticas.

Uno de los puntos a debate lo constituyó la heterogeneidad de manifestaciones que confluían en las programaciones. Si bien el Foro se abrió como un espacio para presentar músicas con un perfil novedoso, desde el primer momento aglutinó una extensa diversidad de obras. Se hablaba, entonces, de que no era posible considerar nuevas las obras cuyas técnicas de composición ya habían sido trabajadas desde hacía décadas o ya tenían un tiempo considerable de haber sido creadas y estrenadas (Brennan 1983: 17).

En un principio, Enríquez expresaba que la música nueva consistía en aquellas manifestaciones que se desarrollaban en ese tiempo y que el Foro se abría con objeto de dar cabida a las novedosas corrientes musicales (Camargo 1979: 37). Sin embargo, poco después, él mismo estableció que lo importante era programar música tomando en cuenta solamente su calidad, de tal forma que en adelante poco importaría si se trataba de obras vanguardistas, nacionalistas o románticas (Ávila 1986: 23)23. De igual forma, el estreno de partituras cobró preeminencia sobre lo nuevo en el sentido de novedad a ultranza, y comenzaron a abundar formatos más "tradicionales" en la programación.

19 Enríquez, Susana. Entrevista con el autor. Ciudad de México, 23 de agosto de 2014.

20 A partir de 1982 el musicólogo Aurelio Tello fue un colaborador cercano a Manuel Enríquez en la constitución del Foro. Incluso, después de la muerte de Enríquez llegó a pensarse que este investigador se quedaría a cargo del certamen. Tello, Aurelio. Entrevista con el autor. Ciudad de México, 13 de mayo de 2015.

21 Soto Millán, Eduardo. Entrevista con el autor. Ciudad de México, 19 de mayo de 2014.

Para dar una idea de lo que expone Eduardo Soto Millán, al analizar una muestra de la programación de diez de las emisiones a cargo de Enríquez, se observa que en todas ellas tenían participación cuatro compositores mexicanos: Mario Lavista, Federico Ibarra, José Antonio Alcaraz y el propio Manuel Enríquez. En otras palabras, cuatro compositores mexicanos siempre presentaban su obra en el Foro. Luego, entre los que participan un ochenta por ciento de las veces se encuentran Arturo Márquez, Alicia Urreta, Manuel de Elías, Víctor Médeles, Francisco Núñez, Héctor Quintanar y Eduardo Soto. Es decir, que diez compositores y una sola compositora son los que tenían mayor cobertura en el Foro, no obstante que en la muestra de programas revisada se contabilizaron alrededor de cincuenta compositores de origen mexicano que participaron de manera más ocasional, o incluso solamente en una emisión. Véanse programas del Foro Internacional de Música Nueva: 1-2,4,6,8-13.

22 En este artículo se da voz a varios compositores.

23 Al igual que en Cardona 1983, en este artículo se da voz también a varios compositores. 
Aunque la visión que empezó a prevalecer en el Foro era la de un espacio sumamente abierto y heterogéneo, esto no respondía del todo a la realidad, ya que no todo cabía en él. En este sentido, Federico Ibarra asentó que las programaciones no siempre reflejaban la pluralidad de tendencias de la música contemporánea pues tendían a quedarse en una línea específica. Algo parecido llegó a plantear Julio Estrada quien pensaba que en el Foro no tenían lugar todas las propuestas (Cardona 1982: 22-23).

Autores como Daniel Catán no alcanzaban a comprender los criterios de selección, y cuestionaban las razones de invitar a determinados músicos extranjeros, que no parecían ser especialistas ni hacían aportes significativos. Igualmente, lamentaba que la música mexicana casi no se ensayara (Cardona 1982: 22). Varios músicos denunciaron la reincidencia de autores en las programaciones y sugirieron que se añadieran nuevos nombres (Cardona 1982: 22). Se llegó a plantear que se incluyera únicamente una sola obra por autor ${ }^{24}$, y se consideró la conveniencia de que la responsabilidad de las programaciones, y en sí la propia organización, no recayera en una sola persona, en este caso Manuel Enríquez, sino en un comité que atendiera los intereses y sugerencias de los compositores de México.

Entre los cuestionamientos más enérgicos a la organización y orientación que daba Manuel Enríquez al Foro se encuentran los de Raúl Cosío Villegas. Cerca de concluir la era del Foro bajo responsabilidad de Manuel Enríquez, este crítico señalaba que los conciertos revelaban una visión más bien estrecha de la música (Cosío 1993). Cosío percibía al Foro como un evento meramente burocrático del que solo se favorecía el propio Enríquez y la gente más cercana a él, por lo que no le veía mayor valor dentro del escenario musical (Cosío 1995).

A pesar de las réplicas y controversias, el Foro hizo múltiples aportes al panorama musical mexicano de la época ${ }^{25}$. Uno de sus puntos sustanciales es que se tornó en un espacio estable para la recepción de estas músicas, lo que propició la interpretación de numerosas obras de compositores nacionales -muchas de estas en calidad de estreno-, así como de autores internacionales.

Durante el tiempo en que Enríquez estuvo al frente de la organización del Foro Internacional de Música Nueva, ya en sus primeros años como parte de las actividades del Cenidim, o posteriormente dentro de la Dirección de Música del INBA, hoy Coordinación Nacional de Música y Ópera, se consolidó -como sugiere Aurelio Tello-, como una ventana de la creación actual, pues la constancia que logró tener el Foro, no alcanzada por otros esfuerzos, aunada a la capacidad de su fundador de vincular a compositores e intérpretes de otras latitudes, contribuyeron decisivamente a que este espacio se convirtiera en un punto referencial para la música y se tendiera una importante relación entre la creación musical mexicana y la extranjera (Tello 2003: 205-307).

24 Soto Millán, Eduardo. Entrevista con el autor. Ciudad de México, 19 de mayo de 2014.

25 Fueron varios los que señalaron la importancia que el Foro tenía para ellos. Así lo manifestaron en distintos espacios: "El II Foro beneficia sobre todo al autor, quien durante todo el año no cuenta con otro evento similar que brinde apoyo y estímulo, aseguró el pianista Jorge Suárez [...]”. "El Foro Internacional de Música Nueva se efectuará del 17 al 27 de abril en el D.F.", Uno más uno (10 de abril, 1980), p. 18 .

"Finalmente, acaso la cualidad más encomiable de la decidida concepción del Foro como proyección y apoyo a los abandonados autores nacionales [...]”, véase Moreno 1980: IX.

"Ha generado el Foro un espacio para una expresión artística que ha sido marginada por instituciones, escuelas e intérpretes [dice Federico Ibarra]”, véase Cardona 1982: 22.

[Dice H. Quintanar] "En México, si no fuera por el Foro y otras manifestaciones aisladas en la UNAM y en la UAM, estaríamos muertos los compositores contemporáneos”, véase Ávila 1986: 23. 
En suma, aunque el Foro cubrió en esta fase un espacio para la música contemporánea, la crítica puso en evidencia que este no era suficiente. No obstante, es de justicia señalar que Manuel Enríquez, artífice del Foro, le dio un impulso vigoroso al certamen y le imprimió un sesgo particular que emanaba de la visión que él tenía de la música de su tiempo.

\section{EL FORO INTERNACIONAL DE MÚSICA NUEVA MANUEL ENRÍQUEZ}

El Foro Internacional de Música Nueva tuvo la virtud de generar su propia inercia y convertirse en un referente estable para la música de reciente factura, de tal suerte que después de la muerte de Manuel Enríquez no fue interrumpido; por el contrario, comenzó un proceso de reestructuración bajo responsabilidad del INBA. Así, a partir de la edición de 1994, el Foro recibió el nombre de su fundador, y se acordó que en las subsiguientes emisiones se tocara una obra de dicho compositor a manera de homenaje.

Es significativo que el Foro no desapareciera, pues, como señala Juan Arturo Brennan, en un país como México, caracterizado por la transitoriedad sexenal presidencial, hablar de permanencia de un proyecto musical es muy difícil (Brennan 2008: 9). De ahí que sea exaltable la labor de Enríquez, quien tuvo en su tiempo la suficiente autoridad y estatura artística para poner cimientos sólidos a un proyecto necesario para la música mexicana que rindió frutos de indudable valor (Brennan 2008: 9). Es interesante observar de manera cuantitativa lo anterior, pues para la decimoquinta emisión, la penúltima en la que estaría al frente Enríquez, el Foro de Música Nueva había celebrado 247 conciertos, presentado 1327 obras, de las cuales el 95\% eran estreno en México, y más de la mitad de estos eran de compositores nacionales ${ }^{26}$.

Esta segunda etapa del Foro que inició tras la desaparición de su fundador atestigua varios cambios. Por principio, el respaldo obtenido por parte del INBA por medio del Departamento de Música, condujo al Foro hacia un proceso de institucionalización, con lo que pasó a formar parte de las actividades regulares de esas instancias. De ahí que se hiciera necesario replantear el concepto mismo del Foro, así como los criterios y objetivos que le darían fundamento. Esta situación devino en la publicación de una convocatoria con objeto de conformar la programación, así como en el establecimiento de un cuerpo colegiado que dictaminara las obras ${ }^{27}$.

Bajo los nuevos esquemas de selección aumentó el número de compositores participantes, es decir, se pluralizó el acceso a este espacio y empezaron a ser incluidos en las programaciones músicos de diversas generaciones y grados de estudio, que iban desde aquellos estudiantes en proceso de formación hasta compositores consolidados y de larga trayectoria. Esto se traducirá en un panorama con mayores problemas a resolver, sobre todo a la hora de seleccionar las obras ${ }^{28}$.

Se pensaba que la integración de un comité de selección daría un giro democrático al evento. Se trataba de evitar, además de que las decisiones recayeran en una sola persona, que se programaran varias obras de un mismo autor-como llegaba a suceder anteriormente- por

26 Presentación a la programación del XV Foro Internacional de Música Nueva (1993): 6.

27 Fue el pianista Fernando García Torres, entonces director del Departamento de Música del INBA, quien tomó la iniciativa de convocar a un grupo de compositores para seleccionar las obras que conformarían el programa del Foro. El primer comité de selección estuvo conformado por: Eduardo Soto Millán, Luis Jaime Cortez y Julio Estrada.

28 Desde el 2009 el comité de selección del Foro recibe alrededor de 400 obras vía convocatoria. Ante esta demanda, el certamen procura dar sitio a un promedio de cien obras por emisión. Soto Millán, Eduardo. Entrevista con el autor. Ciudad de México, 19 de mayo de 2014. 
lo que la comisión también vería que únicamente se seleccionara una obra por compositor. Se buscó, además, que entre sus integrantes prevaleciera la diversidad en cuanto a intereses musicales y estéticos, y que en lo posible pertenecieran a diferentes generaciones. También se estipuló que este cuerpo colegiado estuviera conformado por tres personas y que cada año se integrara una nueva y saliera aquella que llevara más tiempo; es decir, que cada miembro no podría estar más de tres años como jurado 29 .

Si bien los lineamientos señalados se han cumplido en varias emisiones, se percibe en diferentes programas que esto no siempre sucede así, particularmente en lo que concierne a los integrantes de la junta. Según observa Eduardo Soto Millán, aunque se desea que la comitiva represente intereses distintos, se dan casos en que, debido a la afinidad entre sus miembros, la programación llega a dar preferencia a ciertos lenguajes y omitir otros; incluso se ha llegado a señalar cierta predilección en los programas por estudiantes de algunos integrantes de la comisión ${ }^{30}$.

Es probable que todos estos contratiempos se correspondan, en parte, a que esencialmente son compositores quienes conforman tal consejo. Poco espacio ha habido para intérpretes y ha sido nula la inclusión de otros perfiles como críticos o investigadores que no poseen una trayectoria en el ramo de la composición o la interpretación, por ejemplo. Quizá esta situación haya contribuido a acotar las posibilidades de diversificación en la selección de obras.

Otro asunto de suma importancia es que el cuerpo colegiado no tiene autonomía. Esto es, que en buena medida las decisiones de quienes integran el comité pasan por el visto bueno, la decisión o invitación de quien presida en esos momentos la Coordinación Nacional de Música y Ópera del que depende directamente el Foro. Incluso, es frecuente que el propio coordinador de tal dependencia se adscriba a la comisión seleccionadora, en particular cuando este es un compositor. Así, aunque el cuerpo colegiado tenga pautas convenidas - muchas veces aplicadas-, también se adapta en cierta medida a la visión de quien esté al frente de la citada Coordinación. Por decir un ejemplo, cuando Eduardo Soto estuvo al frente de Música y Ópera, propuso que el jurado lo integraran dos compositores mexicanos y uno extranjero, a razón de que el Foro es un certamen de corte internacional ${ }^{31}$. $\mathrm{Al}$ poco tiempo de su salida de la Coordinación, tal idea dejó de llevarse a cabo.

Ahora bien, aunque la inclusión de generaciones diferentes dentro del comité se cumple -en general hay menores de cuarenta años y mayores de cincuenta-, no ha de perderse de vista que los coordinadores de Música y Ópera no responden a ese principio. Es decir, lo constante es que rebasen los cincuenta años, situación que probablemente diluya la mirada multigeneracional. A pesar de todo, debido a la constante presencia de tal cuerpo colegiado a partir del deceso de Enríquez, resulta evidente que la comisión se vuelve una normativa importante de esta nueva era del Foro.

Efectivamente, en la segunda era del festival se lleva a cabo una suerte de reacomodo en donde se busca una mayor horizontalidad. Al no estar ya replegado el Foro a una sola figura, se consigue una mejor distribución, evitando la acumulación del capital específico en una sola entidad. Es decir, se verifica una transformación del organismo más allá de la estructura que le confería la figura de Manuel Enríquez. Sin embargo, las reglas asociadas a este entramado social no cambian del todo. Por un lado, quedan resabios más o menos visibles

29 Soto Millán, Eduardo. Entrevista con el autor. Ciudad de México, 19 de mayo de 2014.

30 Soto Millán, Eduardo. Entrevista con el autor. Ciudad de México, 19 de mayo de 2014.

31 Soto Millán, Eduardo. Entrevista con el autor. Ciudad de México, 19 de mayo de 2014. Fue el compositor español Carlos Cruz de Castro quien formó parte del comité de selección en esas emisiones. Corresponden a los certámenes XXXIII a XXXV (2011-2013). 
de la estructura original del Foro, como el que continúe al alero de la misma institución, es decir, el INBA. Esta circunstancia da pautas respecto de los fines y posibilidades de este organismo, lo que se traduce, por ejemplo, en la definición de los espacios en los que se desenvuelve -los del propio Instituto-, en incluir cierto repertorio en la programación ${ }^{32}$, en la difusión que se da al evento y en el presupuesto con que cuenta. Por otro lado, hay aspectos, quizá de manera menos evidente, que también permanecen, los que consisten en la asimilación de prácticas en el desarrollo del Foro, esto es, un habitus.

El Foro de Música Nueva constituye, como se ha señalado, un campo asociado a una concepción musical y a un sector social determinado. Cómo percibe este grupo esa música, queda plasmado en buena medida en la programación del evento y más recientemente en su convocatoria. Estos elementos del Foro ayudan a ver las estructuras internas que se han establecido en este, es decir, que podemos visualizarlos precisamente como vehículos del habitus. De estos aspectos se pueden destacar dos que han sido consustanciales al Foro y han incidido en su realización. Uno es la priorización del formato concierto de cámara, y otro, la preeminencia de la música escrita.

La inclusión casi exclusiva de obras escritas ha sido una constante en las dos etapas del Foro. En su época, Manuel Enríquez declaraba que había muchos jóvenes que querían participar en el Foro pero todavía no sabían escribir correctamente una partitura (Ramírez 1991: 27). Asimismo, Eduardo Soto Millán repara en que, ante la abrumadora cantidad de obras que recibe el Foro, las comisiones dictaminadoras muchas veces se centran en cuidar que las obras que se dejan fuera de la programación se excluyan por cuestiones de calidad, entendiendo por esto que sean aceptadas aquellas que estén correctamente escritas ${ }^{33}$.

Esto permite observar que en el Foro se ha dado un peso decisivo a la escritura y se ha establecido una suerte de ideal de la misma. Más allá de pensar la grafía musical como medio comunicativo entre un compositor y un intérprete, la preponderancia por lo escrito deviene en una manera de condicionar el tipo de obras y en un filtro importante para la música que tenga una distancia hacia esta. En los términos que se ha venido dando esta situación, llama la atención que esto se dé como algo natural, como si toda la música generada durante los años que ha tenido vida el Foro estuviera necesariamente plegada a dicho aspecto.

A grandes rasgos, la convocatoria para concursar con una obra establece a la escritura como un punto preponderante para poder participar. No obstante que se contempla un apartado referido a obras que incluyan electrónica (para estas se solicita que envíen los audios), también se aclara que se dará preferencia a obras para dotaciones específicas, lo que tiende a una instrumentación acústica. A pesar de que en algunos años se han incluido entre las dotaciones prioritarias las de medios electrónicos, se entiende que, si es en combinación con un instrumento acústico, debe pasar por lo escrito. Se observa, pues, que en la redacción de la convocatoria la partitura juega un papel prominente que articula de forma sustancial el eje de la programación, además del formato de música de cámara.

32 Por ejemplo, en la emisión XXXVI del Foro Internacional de Música Nueva, se realizó un programa entero dedicado a la obra de Manuel Enríquez interpretado por el ensamble Cepromusic. Juan Pablo Medina, miembro del comité de selección de ese año, explica que al llevar a cabo la programación debían tener previsto dicho homenaje luctuoso a Enríquez. Así, aunque la comisión recibió con entusiasmo tal concierto, no estaba propiamente en sus manos decidir acerca de su realización (Medina, Juan Pablo. Entrevista con el autor. Ciudad de México, 28 de mayo de 2014).

33 Soto Millán, Eduardo. Entrevista con el autor. Ciudad de México, 19 de mayo de 2014. 
El texto de la convocatoria del Foro suele abrirse con el postulado de ser incluyente con todas las tendencias de la música actual, pero es posible preguntarse ¿qué pasa con aquellas músicas que no poseen propiamente un desarrollo escrito? Por ejemplo, el llamado live coding se expresa en términos algorítmicos y parte sustancial de su práctica consiste en ir desarrollando la propuesta sonora en el mismo momento de su ejecución, e ir observando la construcción del algoritmo; o bien el extenso terreno de la improvisación libre, cuyas características abarcan lo espontáneo y se distingue por la ausencia de partituras -en su sentido más convencional- o estructuras cerradas o predeterminadas. Lo mismo puede decirse de las propuestas con multimedia o de colaboraciones interdisciplinarias. Bajo los parámetros de la convocatoria ¿cómo podrían evaluarse estas músicas?

Desde esta perspectiva se genera una distancia con varias propuestas sonoras -que incluso podrían devenir "más nuevas"- que muchas realizadas mediante el soporte escrito de la partitura de notación occidental. En este sentido, puede advertirse una suerte de paradoja en la convocatoria, donde al tiempo que se busca constituir un ejercicio democrático a favor de la diversidad de obras, también genera un impasse a muchas otras formas y medios de expresión sonora. Dicho lo anterior, se entiende entonces que aquello que se puede juzgar como nuevo en este certamen de música nueva es una construcción atravesada por diferentes tamices y posiciones, por lo que eso nuevo no es algo abierto ni neutro. Más bien, la idea de música nueva se erige desde parámetros específicos que modelan la composición del certamen.

Si hasta 1994 fue Manuel Enríquez quien dio dirección a lo que tendría presencia en el Foro de Música Nueva, tras su muerte, la función de Enríquez sería asumida por la convocatoria y el cuerpo colegiado que se encarga de ella y de la selección de obras. Es interesante resaltar que, con su fundador o sin él, el concepto del Foro es parecido, esto es, que las programaciones y los formatos de los conciertos tienen muchas semejanzas. Cabría preguntarse si la música ha tenido esa estabilidad, o si es más un habitus el que ha ralentizado la visibilidad de otros panoramas musicales en el desarrollo del Foro ${ }^{34}$.

Llegados a este punto, es preciso señalar que bajo la conformación actual del Foro algunos músicos consideran poco atractiva la convocatoria, pues no ven reflejados sus intereses en esta, ni les resultan atractivos sus lineamientos y el formato del festival. Habría, pues, expresiones que tienen poca posibilidad de ser programadas, y para las que tampoco habría espacios adecuados para su interpretación. Esto sugiere el músico Wilfrido Terrazas, para quien la música parcialmente escrita, las obras abiertas, las expresiones como la improvisación libre con interdisciplina o el extenso campo del arte sonoro, y en sí las músicas fuertemente vinculadas a la tecnología, no tienen propiamente un sitio en las programaciones. Lejos de que se vean reflejadas en los intereses del Foro, se observa una notoria predilección por la música de concierto en un formato "tradicional" 35.

Como ya se advertía, el papel que se confiere a la escritura no es lo único que le da una forma específica al Foro, también lo hacen los espacios en los que se desarrolla y el formato que adquieren los conciertos. Considerando estos aspectos, se observa que el tipo de música que se ofrece en el evento tiene lineamientos bastante definidos; que pocas veces hay posibilidad de ir más allá de estos, salvo en casos más bien aislados ${ }^{36}$, y muchas veces bajo

34 En las más recientes emisiones del Foro se ha verificado la inclusión de formatos que conllevan mayor apertura a otras formas de escucha y performáticas. Sin embargo, si observamos la generalidad de la programación, su tendencia es la de reproducir los parámetros esbozados.

35 Terrazas, Wilfrido. Entrevista con el autor. Ciudad de México, 3 de julio de 2014.

36 Por ejemplo, en la emisión de 2014, fueron presentadas como parte de las actividades del Foro esculturas sonoras de los artistas François y Bernard Baschet, que tienen un carácter interactivo. Parte 
el impulso de personajes concretos, y no como una constante del certamen. Frente a este horizonte, donde las obras tienen que ajustarse a un entorno preestablecido, corresponde preguntarse si es posible que el Foro pudiera enriquecer su formato.

Volvemos a los planteamientos de Pierre Bourdieu, cuando establece que es la posesión de una configuración particular de propiedades lo que legitima el derecho de entrar a un campo, es decir, poseer cierto capital específico (Bourdieu y Loïc 1995: 72). En este caso, los términos en que se da la convocatoria, que tienen que ver con un formato establecido tanto del concierto como de la obra, son una suerte de condicionamiento que demanda del sujeto poseer determinadas habilidades y conocimientos, una forma de capital específico que le darían un "derecho de entrada" al campo. Sería debido al habitus que estas características perdurarían a lo largo de los años y fungirían como reglas de juego y lugares de poder. En el caso del Foro, esto podría traducirse en que los lineamientos de las convocatorias operan como una forma importante de condicionamiento para ser incluido en la estructura del Foro, y en estas mismas también se hallaría un vehículo donde se habrían privilegiado ciertas formas de saber y hacer, en este caso, maneras de entender y ejercer el oficio musical, que van más allá de quién esté al frente de la organización del festival.

Todas estas condiciones, también van definiendo a un público. Es importante tener en cuenta que el evento se desarrolla en un mismo tipo de lugar, preferentemente en salas de conciertos y auditorios; es decir, su espacio no es el de la plaza pública o la radio, por ejemplo. Sus actividades están, casi, confinadas al espacio del auditorio, con un formato bastante definido que es el del concierto de música de cámara u orquestal. Esta situación provoca muchas veces que a las salas de conciertos concurra casi exclusivamente el llamado público "de la música nueva", es decir, estudiantes de escuelas de música, compositores, intérpretes y algunos involucrados con el arte contemporáneo; esto comprende, en buena medida, a la misma gente que produce este tipo de música ${ }^{37}$.

Las características bajo las que se desarrolla el Foro modelan una idea de la música nueva o contemporánea que, pretendiéndolo o no, nubla la posibilidad de otras formas de entenderla, y limita en gran medida el tipo de obras participantes. La inclusión de obras queda, pues, condicionada a un tipo más o menos específico, delimitado: obras soportadas de manera preferente en partitura, con un modelo de escritura que se tome por adecuado, en formato de música de cámara, en el espacio de una sala de conciertos "convencional", con un tipo de escucha priorizado, esto es, con el público de frente al ensamble, sentado y en silencio.

Es evidente que, un evento de la magnitud del Foro de Música Nueva ha atravesado un sinfín de intentos de renovación y de integración de nuevas propuestas, pero a lo largo de sus programaciones se observa una constante en sus características, mismas que se perciben muy incorporadas a su práctica, y que de alguna manera se han naturalizado. Quizá esto responda a que -como señala Bourdieu-, cuando el habitus entra en relación con un mundo social del que es producto, es como un pez en el agua y el mundo se le aparece como obvio (Bourdieu y Loïc 1995: 73). Posiblemente, el escenario construido por el Foro ha caído en dicha situación y por esto quizá no parecería necesario repensar a profundidad su conformación. Desde esta óptica, puede observarse cómo el tránsito de la

de esta exposición incluyó sesiones de improvisaciones guiadas, dirigidas a niños. Igualmente, en la emisión subsiguiente se comisionó una obra (Fonomicroscopía del D.F.) a la compositora francesa Carole Chargueron para presentarla en el Espacio Experimentación Sonora del MUAC-UNAM -una sala multicanal-en el marco de la edición XXXVII del Foro. Véase respectivamente: Programa de actividades del XXXVI FIMNME, (2014): 8. / Programa de actividades del XXXVII FIMNME, (2015): 8-9.

37 Terrazas, Wilfrido. Entrevista con el autor. Ciudad de México, 3 de julio de 2014. 
primera etapa del Foro a la segunda no implicó un cambio significativo en su estructura, pues las estructuras internas, contenidas en el habitus, han perdurado ${ }^{38}$. La convocatoria y el formato para las obras en esta segunda etapa del Foro han tenido un papel preponderante en la subsistencia del habitus. No es que el Foro esté cerrado o sea un proyecto acabado, sino que tras de sí tiene una inercia muy grande, con un peso histórico importante, y además interactúa con estadios de la promoción cultural de México que lo convierten en una estructura compleja y de una dimensión muy extensa; esto dificulta la posibilidad de mirar su trayectoria presente y futura desde otros horizontes.

\section{CONCLUSIONES}

Desde su inauguración y hasta 1994, año en que Manuel Enríquez murió, esta estructura social que es el Foro estuvo estrechamente ligada a dicho músico. Fue en su figura donde se concentró lo que Bourdieu llama capital específico, es decir, ciertos atributos y valores que dan fundamento de autoridad y poder (Bourdieu 1990: 109-111), mismos que le permitieron cohesionar el Foro y establecer buena parte de su dinámica. Así, Enríquez formuló un proyecto dinámico marcado por el impulso y difusión de aquellas expresiones relegadas de otros espacios institucionales caracterizadas por su originalidad y novedad. Pero aquella vitalidad, que le fue característica en sus inicios, comenzó a perderse al cabo de los años y adquirieron peso aspectos como el "estreno en México" o "la calidad". Esto es, ya no consideró propiamente la tendencia, el lenguaje, la estética e incluso la temporalidad de la obra.

Así, lo nuevo queda sujeto a la aprobación de ciertos filtros: la escritura y el formato de música de cámara, así como al hecho de que el desarrollo de la obra sea técnicamente posible y viable para las configuraciones de ejecución del INBA. Aunque estas condiciones han sido una suerte de continuum que se ha dado a lo largo de ambas etapas, la que se desarrolló bajo la responsabilidad de Manuel Enríquez y la que sigue después de su fallecimiento. En la primera de ellas el peso mayor de las decisiones recaía en el citado compositor, mientras que en la segunda el peso recae en la convocatoria y en el comité de selección.

En efecto, una de las diferencias significativas entre las dos fases del Foro planteadas en este estudio es que en la primera era una sola persona, en este caso Enríquez, quien respaldaba la propuesta del certamen, asumía plena dirección y tomaba las decisiones. Por tanto, una parte sustancial de los frutos del festival en esta fase deben serle adjudicados al compositor. Lo mismo corresponde decir acerca de las críticas a la organización y los desaciertos que pudieron existir: estos también recaen, esencialmente, en el músico jalisciense. Así, la ausencia de Enríquez conllevó la desaparición de ese personaje central que había presidido el Foro desde sus inicios, y dio lugar al surgimiento de nuevos mecanismos de organización. El peso mayor lo adquiere entonces no ya una figura unitaria, responsiva, sino una institución a cuyo cargo queda el lanzamiento de las convocatorias y la designación de los sucesivos comités de selección.

38 Es más, el formato del Foro y sus contenidos tampoco han tenido mayores transformaciones pese a las alternancias gubernamentales que ha tenido México: la entrada del Partido Acción Nacional (PAN) a la presidencia en el año 2000 -luego de setenta años en el poder del Partido Revolucionario Institucional (PRI) - con Vicente Fox Quezada, luego sucedido por el también panista Felipe Calderón en 2006; así como con el regreso del PRI a la presidencia en 2012 con el mandato de Enrique Peña Nieto. Actualmente se vive otra transición con la llegada a la presidencia en 2018 de Andrés Manuel López Obrador, representante del partido Movimiento Regeneración Nacional (Morena). A pesar de los distintos giros en materia de administración de instancias culturales y proyectos, el Foro ha seguido su curso sin mayores alteraciones. 
En las dos formas con las que ha funcionado el Foro se observan pros y contras. En la primera etapa se siente verticalidad en las decisiones, tomadas a partir de los designios del principal responsable. Aunque en su día fueron varios los músicos que criticaron negativamente esta estructura, hubo otros a quienes les parecía importante contar con una figura concreta a quien poder dirigirse para sugerir cambios o, en tal caso, entregar en persona su obra y defender sus argumentos para favorecer la inclusión en las programaciones. La rotación del comité de selección que caracteriza la nueva organización del Foro ha dado a este un sentido más democrático e incluyente, lo que supone la aceptación de más compositores y tendencias. Pero también implica un proceso de institucionalización que ha desdibujado la figura responsiva del festival, circunstancia que al parecer ha dejado sin interlocutor a los interesados en una participación más directa. Resulta evidente que una y otra etapa ha favorecido la actualización del certamen; no obstante, convendría analizar a fondo en qué medida cada una de ellas ha privilegiado el sentido de apertura, inclusión y novedad que motivó tanto la fundación del Foro como su posterior desarrollo, y en qué medida han demostrado su eficacia al verificar en sus programaciones las más recientes formas de concebir e interpretar la música.

La estructura del Foro Internacional de Música Nueva ha apostado por la preeminencia de una música con características específicas y por ello se ha convertido en un espacio de oportunidades para compositores de un determinado perfil. De esta forma, a lo largo de su existencia, los escenarios del Foro han dado cuenta de un extenso número de obras y autores que responden a esa línea establecida. Sin duda, el certamen es hoy un espacio importante para estas expresiones y autores. No habría que olvidar, sin embargo, que actualmente hay un extenso número de compositores creando su música desde otros ámbitos y basados en distintas premisas: las obras y la participación de la mayoría de ellos se ha visto relegada en este espacio. Es posible que, la cuarta década del Foro apunte hacia su renovación, sobre todo a partir de la reciente inclusión de instituciones y espacios con otras orientaciones ${ }^{39}$, que en años recientes impulsan nuevas propuestas. Tal situación probablemente pueda apuntalar hacia una tercera fase del Foro que también dé respuesta a esas otras realidades musicales.

\title{
BIBLIOGRAFÍA
}

\author{
Aharonián, Coriún \\ 1994 "La muerte de Manuel Enríquez", Revista Musical Chilena, XLVIII/182 (julio-diciembre), \\ pp. 121-126. \\ Alcaraz, José Antonio \\ 1977 "El oído se aguza para ensartar un eco", Proceso, 38 (23 de julio). https://hemeroteca. \\ proceso.com.mx [acceso: 26 de mayo de 2021].
}

2001 Manuel Enríquez. Canciones para un compañero de viaje, Ciudad de México: INBA-Cenidim.

Alonso Minutti, Ana R.

2014 "La 'destrucción renovadora' de Quanta", Pauta. Cuadernos de teoría y crítica musical, XXXII/130 (abril-junio), pp. 22-34.

39 Por citar algunos ejemplos, el del Museo Arte Alameda; el jardín sonoro de la Casa del Lago "Juan José Arreola" de la UNAM, que propicia otras formas de escucha y de experimentar un concierto; o la inclusión de espacios de danza como el teatro Guillermina Bravo del Centro Cultural del Bosque de la Ciudad de México, lo que supone un lugar para el encuentro de danza y música, que en los primeros años de vida del Foro llegó a tener un lugar importante. 
Ávila, Norma

1986 "No ha muerto el Nacionalismo, ni tampoco tenemos derecho a matarlo: Quintanar", Uno más uno (6 de mayo), p. 23

Bourdieu, Pierre

1990 Sociología y cultura. Ciudad de México: Grijalbo.

2002 La distinción. Criterio y bases sociales del gusto. Ciudad de México: Taurus.

2009 El sentido práctico. Ciudad de México: Siglo XXI.

Bourdieu, Pierre y Loḯ J.D. Wacquant

1995 Respuestas. Por una antropología reflexiva, Buenos Aires: Grijalbo.

Brennan, JuAn Arturo

1983 "Vista al Foro 83 / I", Uno más uno (23 de abril), p. 17.

2008 "Tres décadas de música contemporánea" texto introductorio a la programación de la trigésima edición del Foro Internacional de Música Nueva Manuel Enríquez, Ciudad de México: INBA, p. 9.

Camargo, Angelina

1979 "El INBA presentó un Foro de Música Nueva”, La prensa (7 de abril), p. 37.

Cardona, Patricia

1982 "Ejecuciones poco menos que vergonzosas en el Foro de Música Nueva, opina el pianista Federico Ibarra", Uno más uno (25 de marzo), p. 22.

1983 "El FMN, un esfuerzo que se debe apoyar, dice Mario Lavista", Uno más uno (26 de marzo), p. 23.

Carredano, Consulelo

2000 Joaquín Gutiérrez Heras. La poética de la libertad, Ciudad de México: INBA-Cenidim.

Cosío Villegas, Raúl

1993 "El festival contemporáneo", El Universal Gráfico (31 de mayo), p. 17.

1995 "Oratorios polacos", El Universal (24 de mayo), p. 21.

DE ANDRAde, Iracema

2014 "Antecedentes históricos de la música electroacústica en América Latina". Conferencia inédita. Ciudad de México, Cenidim (agosto).

Enríquez, Susana, Aurelio Tello e Iracema de Andrade

2017 Manuel Enríquez. Hoy de ayer, Ciudad de México: Secretaría de Cultura-Cenart.

Gómez Rivas, Armando

2013 "Instituciones musicales. La conformación de una cultura musical en el siglo XX", La música en los siglos XIX y XX. Ricardo Miranda y Aurelio Tello (coordinadores). Ciudad de México: CONACULTA, pp. 371-415.

GonZález, María Ángeles y Leonora SaAvedra

1982 Música contemporánea mexicana, Ciudad de México: SEP-FCE.

Hobsbawm, ERIC

1995 Historia del siglo XX, Barcelona: Crítica.

Kuri Aldana, Mario

1976 "Los jóvenes compositores mexicanos", Heterofonía. Revista Musical IX/5 (septiembreoctubre), pp. 10-13.

Marco Aragón, Tomás

2002 Pensamiento musical y siglo XX, Madrid: Fundación de Autor. 
Melo, JuAn Vicente

1994 Notas sin música, Ciudad de México: FCE.

Molino, JeAn

2011 "El hecho musical y la semiología de la música", Reflexiones sobre semiología musical. Susana González Aktories y Gonzalo Camacho Díaz (coordinadores). Ciudad de México: UNAMENM, pp. 111-172.

Moreno Rivas, Yolanda

1980 "Instrumentarium", Siempre (21 de mayo), p. IX.

1994 La composición en México en el siglo XX, Ciudad de México: Conaculta.

Picún, OlgA

2006 "Jacobo Kostakowsky en México: una aproximación al contexto musical de los años treinta”, Anales del Instituto de Investigaciones Estéticas, 88, pp. 169-202. DOI: doi.org/10.22201/ iie.18703062e.2006.88.2211

Prieto, Carlos

2013 Variaciones de voltaje, Ciudad de México: Universidad del Claustro de Sor Juana.

Pulido, Esperanza

1978 "Conciertos", Heterofonía. Revista Musical, XI/6 (noviembre-diciembre), p. 33.

RAMÍREZ, FERMín

1991 "En las escuelas de música solo se enseña el siglo XIX”, Uno más uno (26 de abril), p. 27.

Rocha Iturbide, MANuel

2012 "Arqueología de la música experimental en México". (Ready)Media: hacia una arqueología de los medios y la invención en México. Karla Jasso y Daniel Garza (editores). Ciudad de México: Laboratorio de Arte Alameda-INBA, pp. 215-230.

Ruiz, Xochiguetzal

1999 "Cenidim", Diccionario de la música española e hispanoamericana. Emilio Casares Rodicio (director). Vol. 3. Madrid: Sociedad General de Autores y Editores, pp. 476-478.

SAAVEDRA, LEONORA

1999 "Enríquez Salazar, Manuel". Diccionario de la música española e hispanoamericana. Emilio Casares Rodicio (director). Vol. 4. Madrid: Sociedad General de Autores y Editores, pp. 677-683.

Sosa, Octavio, COOMP.

2008 José Antonio Alcaraz a través de sus textos, Ciudad de México: Conaculta.

Tello, Aurelio

2003 "Foro de Música Nueva, ventana para la creación contemporánea", México. Su apuesta por la cultura. Armando Ponce (coordinador). Ciudad de México: Proceso/UNAM/Grijalbo, pp. 305-307.

2010 "La creación musical en México durante el siglo XX”, La música en México. Panorama del siglo XX. Aurelio Tello (coordinador). Ciudad de México: FCE, pp. 486-555.

2011 "La música en Latinoamérica del siglo XX hasta nuestros días", La música en Latinoamérica. Mercedes de Vega (coordinadora). Ciudad de México: Secretaría de Relaciones Exteriores, pp. 139-241.

Vilar Payá, Luisa y Ana R. Alonso Minutti

2012 "Estrategias de diferenciación en la composición musical: Mario Lavista y el México de fines de los sesenta y comienzos de las setenta”, Revista Argentina de Musicología. 12-13, pp. 267-289. 